Check for updates

Cite this: Chem. Sci., 2018, 9, 7520

๑ All publication charges for this article have been paid for by the Royal Society of Chemistry

Received 11th May 2018

Accepted 31st July 2018

DOI: $10.1039 / \mathrm{c} 8 \mathrm{sc} 02099 \mathrm{j}$

rsc.li/chemical-science

\section{The effect of iron binding on uranyl(v) stability $\dagger$}

\author{
Radmila Faizova, Sarah White, Rosario Scopelliti and Marinella Mazzanti (D)*
}

Here we report the effect of $\mathrm{UO}_{2}{ }^{+} \ldots \mathrm{Fe}^{2+}$ cation-cation interactions on the redox properties of uranyl( $\left.\mathrm{v}\right)$ complexes and on their stability with respect to proton induced disproportionation. The tripodal heptadentate Schiff base trensal ${ }^{3-}$ ligand allowed the synthesis and characterization of the uranyl( $\left.\mathrm{vl}\right)$ complexes $\left[\mathrm{UO}_{2}\right.$ (trensal) $\left.\mathrm{K}\right], 1$ and $\left[\mathrm{UO}_{2}(\mathrm{H}\right.$ trensal)], 2 and of uranyl( $\mathrm{v})$ complexes presenting $\mathrm{UO}_{2}{ }^{+} \ldots \mathrm{K}^{+}$or $\mathrm{UO}_{2}{ }^{+} \ldots \mathrm{Fe}^{2+}$ cation-cation interactions ([UO $\mathrm{O}_{2}$ (trensal) $\left.\mathrm{K}\right] \mathrm{K}, 3,\left[\mathrm{UO}_{2}\right.$ (trensal)] [K(2.2.2crypt)][K(2.2.2crypt)], 4, $\left.\left.\left[\mathrm{UO}_{2} \text { (trensal)Fe(py) }\right)_{3}\right], 6\right)$. The uranyl(v) complexes show similar stability in pyridine solution, but the presence of $\mathrm{Fe}^{2+}$ bound to the uranyl( $\left.\mathrm{v}\right)$ oxygen leads to increased stability with respect to proton induced disproportionation through the formation of a stable $\mathrm{Fe}^{2+}-\mathrm{UO}_{2}{ }^{+}-\mathrm{U}^{4+}$ intermediate $\left(\left[\mathrm{UO}_{2}\right.\right.$ (trensal) $\mathrm{Fe}(\mathrm{py})_{3} \mathrm{U}$ (trensal)]l, 7) upon addition of 2 eq. of $\mathrm{PyHCl}$ to 6 . The addition of 2 eq. of $\mathrm{PyHCl}$ to 3 results in the immediate formation of $\mathrm{U}(\mathrm{IV})$ and $\mathrm{UO}_{2}{ }^{2+}$ compounds. The presence of an additional $\mathrm{UO}_{2}{ }^{+}$bound $\mathrm{Fe}^{2+}$ in $\left[\left(\mathrm{UO}_{2}\left(\text { trensal) } \mathrm{Fe}(\mathrm{py})_{3}\right)_{2} \mathrm{Fe}(\mathrm{py})_{3}\right] \mathrm{l}_{2}, 8\right.$, does not lead to increased stability. Redox reactivity and cyclic voltammetry studies also show an increased range of stability of the uranyl( $\mathrm{v})$ species in the presence of $\mathrm{Fe}^{2+}$ with respect both to oxidation and reduction reactions, while the presence of a proton in complex 2 results in a smaller stability range for the uranyl( $v)$ species. Cyclic voltammetry studies also show that the presence of a $\mathrm{Fe}^{2+}$ cation bound through one trensal ${ }^{3-}$ arm in the trinuclear complex $\left[\left\{\mathrm{UO}_{2} \text { (trensal) }\right\}_{2} \mathrm{Fe}\right], 5$ does not lead to increased redox stability of the uranyl(v) showing the important role of $\mathrm{UO}_{2}{ }^{+} \ldots \mathrm{Fe}^{2+}$ cation-cation interactions in increasing the stability of uranyl(v). These results provide an important insight into the role that iron binding may play in stabilizing uranyl( $(\mathrm{v})$ compounds in the environmental mineral-mediated reduction of uranium(vi).

\section{Introduction}

Uranyl $(\mathrm{v})^{\mathbf{1}}$ has been proposed as an important transient intermediate in the biological or abiotic mineral-mediated transformation of soluble uranyl(vi) compounds into the insoluble uranium(Iv) dioxide $\left(\mathrm{UO}_{2}\right)$. These processes provide a convenient strategy to sequester uranium in the environment and, as such, are very important for ground-water remediation. In particular, stable adsorbed or incorporated uranyl(v) species have been reported to form during the $\mathrm{U}(\mathrm{VI})$ reduction by $\mathrm{Fe}(\mathrm{II})$ bearing minerals such as mica ${ }^{1 e}$ or magnetite $\left(\left[\mathrm{Fe}^{2+}\left(\mathrm{Fe}^{3+}\right)_{2} \mathrm{O}_{4}\right]\right)^{2,3}$ and the presence of iron as the second nearest neighbour has been identified. ${ }^{4} \mathrm{UO}_{2}{ }^{+}$species have low stability in aqueous media and they quickly disproportionate to uranyl(vi) and U(Iv), ${ }^{5}$ but the incorporation into iron minerals may prevent disproportionation or further reduction of $\mathrm{U}(\mathrm{v})$ to $\mathrm{U}(\mathrm{IV})$ and thus lead to long-term immobilization of $\mathrm{U}(\mathrm{v})$. However, the role of iron

Institut des Sciences et Ingénierie Chimiques, Ecole Polytechnique Fédérale de Lausanne (EPFL), CH-1015 Lausanne, Switzerland. E-mail: marinella.mazzanti@ epfl.ch

$\dagger$ Electronic supplementary information (ESI) available: Full experimental details, NMR, ESI/MS and EPR spectra, cyclic voltammograms and detailed X-ray crystallographic data in CIF format. CCDC 1842376-1842382. For ESI and crystallographic data in CIF or other electronic format see DOI: $10.1039 / \mathrm{c} 8 \mathrm{sc0} 02099 \mathrm{j}$ binding to uranyl(v) species and their stabilization remains ambiguous in spite of its importance for the correct speciation of uranium in the environment.

Dinuclear or polynuclear complexes of uranyl(v) built from the interaction of a uranyl(v) oxo group with the uranium centre from a $\mathrm{UO}_{2}{ }^{+}$moiety $\left(\mathrm{UO}_{2}{ }^{+} \cdots \mathrm{UO}_{2}{ }^{+}\right)$, also known as cation-cation interaction (CCI), ${ }^{6}$ have been proposed as intermediates in the proton promoted disproportionation of uranyl(v) to afford $\mathrm{UO}_{2}{ }^{2+}$ and $\mathrm{U}(\mathrm{IV})$ species. ${ }^{1 c, 7}$ The subsequent addition of protons to these polynuclear uranyl(v) intermediates leads to complete electron transfer followed by dissociation of the resulting $\mathrm{U}(\mathrm{vI}) \cdots \mathrm{U}(\mathrm{Iv})$ complex. In aprotic media stable polynuclear $\mathrm{UO}_{2}{ }^{+} \cdots \mathrm{UO}_{2}{ }^{+}$complexes have been isolated. ${ }^{8}$ We showed that the addition of protons $(\mathrm{PyHCl})$ to a pyridine solution of stable tetrameric $\mathrm{UO}_{2}{ }^{+} \cdots \mathrm{UO}_{2}{ }^{+}$ complexes leads to the immediate disproportionation of the uranyl(v) species affording uranyl(vi) and U(Iv) complexes and water. $^{8 b}$ Disproportionation of polynuclear cation-cation complexes was also observed in the absence of protons upon addition of strong Lewis acids $\left(\mathrm{Li}^{+} \text {or } \mathrm{U}^{4+}\right)^{8 b, 9}$ to stable uranyl(v) Schiff base complexes and was found to lead to complex mixtures of soluble mixed-valent $\mathrm{U}(\mathrm{Iv}) / \mathrm{U}(\mathrm{v})$ uranium oxo clusters. It was also reported that the binding of strong Lewis acids or Group 1 metals to the uranyl(vi) oxo group renders more favourable the reduction of $\mathrm{U}(\mathrm{vI})$ to $\mathrm{U}(\mathrm{v}) .{ }^{\mathbf{1 0}}$ 
Moreover, it has been demonstrated that the binding of strong Lewis acids such as $\mathrm{B}\left(\mathrm{C}_{6} \mathrm{~F}_{5}\right)_{3}$ to the uranyl(v) oxo groups renders more accessible the reduction of $\mathrm{U}(\mathrm{v})$ to $\mathrm{U}(\mathrm{Iv}){ }^{\mathbf{1 0 d , 1 1 , 1 2}} \mathrm{A}$ fewer studies have been directed to investigate the effect of the interaction of uranyl(v) with $3 \mathrm{~d}$ transition metals on the stability and redox reactivity of uranyl(v) species. Moreover, in spite of the fact that several uranyl(v) complexes stable in organic solution have been isolated in recent years,, ${ }^{\mathbf{9}, \mathbf{1 3}}$ only a few examples of heteropolymetallic complexes presenting a $\mathrm{UO}_{2}{ }^{+} \ldots$ $\mathbf{M}$ interaction, where $\mathbf{M}$ is a $3 \mathrm{~d}$ transition metal, have been prepared. ${ }^{14}$ The few reported $\mathrm{UO}_{2}{ }^{+} \cdots 3 \mathrm{~d}$ complexes have shown interesting single-molecule magnetic properties. ${ }^{\mathbf{1 4}}$

The addition of $\mathrm{FeI}_{2}$ to an unstable putative uranyl(v) dipotassium complex of a macrocyclic Schiff base Pacman ligand was reported to result in a higher stability of the uranyl(v) Pacman complexes which was corroborated by the isolation of the corresponding heterobimetallic $\mathrm{UO}_{2}{ }^{+} \cdots \mathrm{Fe}^{2+} \mathrm{CC}$ complex. However, the effect of the interaction $\mathrm{UO}_{2}{ }^{+} \cdots \mathrm{Fe}^{2+}$ on the stability of these uranyl(v) complexes was not further investigated. ${ }^{\mathbf{1 4 c}}$

Here we report two new stable complexes of uranyl(v) supported by the tripodal Schiff base ligand $\mathrm{H}_{3}$ trensal $\left(2,2^{\prime}, 2^{\prime \prime}\right.$-tris(salicylideneimino)triethylamine): the $\mathrm{UO}_{2}{ }^{+} \cdots \mathrm{K}^{+}$ $\left[\mathrm{UO}_{2}(\right.$ trensal $\left.) \mathrm{K}\right] \mathrm{K}, 3$, and the heterobimetallic $\mathrm{UO}_{2}{ }^{+} \cdots \mathrm{Fe}^{2+}$ complex $\left[\mathrm{UO}_{2}(\right.$ trensal $\left.) \mathrm{Fe}(\mathrm{Py})_{3}\right], 6$. The reactivity of these complexes toward protons and their redox properties were compared and these studies unambiguously show the increased stability of the iron bound complexes.

\section{Results and discussion}

\section{Uranyl(vi) and uranyl(v) complexes of trensal ${ }^{3-}$}

The reaction of $\mathrm{K}_{3}$ trensal with the nitrate salt of uranyl (vI) leads to the isolation of the uranyl(vi) complex [ $\mathrm{UO}_{2}$ (trensal)K], 1 in $59 \%$ yield. The broad ${ }^{1} \mathrm{H}$ NMR spectrum of 1 in pyridine suggests the presence of fluxional solution species. A higher resolution of the ${ }^{1} \mathrm{H}$ NMR spectrum is observed in deuterated THF and a well resolved ${ }^{1} \mathrm{H}$ NMR spectrum could be obtained in $\mathrm{CD}_{3} \mathrm{OD}$ solution (Fig. $\mathrm{S} 2 \dagger$ ).

X-ray quality crystals of $\mathbf{1}$ could not be obtained, but the addition of one equivalent of $\mathrm{PyHCl}$ to a pyridine solution of 1 led to the isolation of X-ray quality crystals of the neutral complex $\left[\mathrm{UO}_{2}\left(\right.\right.$ Htrensal)], 2, in $60 \%$ yield. The ${ }^{1} \mathrm{H}$ NMR spectrum of 2 in pyridine shows the presence of 15 overlapping narrow signals in agreement with the presence of $\mathrm{C}_{2}$ symmetric solution species (Fig. S3†).

The X-ray crystal structure of this complex is presented in Fig. 1 and shows that the uranium atom is heptacoordinated, with a slightly distorted pentagonal bipyramidal coordination geometry, by two uranyl oxygen atoms in the axial position and five donor atoms of the trensal ${ }^{3-}$ ligand in the equatorial plane. The third protonated arm of the trensal ${ }^{3-}$ ligand is not coordinated to the uranyl cation and the phenol proton is hydrogenbonded with the Schiff base nitrogen N4. The values of the $\mathrm{U}(\mathrm{vI})=\mathrm{O}$ bond lengths lie in the range of those typically observed for uranyl(VI) complexes (U-O3 = 1.783(3) $\AA$ and U-O4 $=1.787(3) \AA) .{ }^{8 a, d, 9,15}$ The average $\mathrm{U}-\mathrm{O}_{\text {phenoxide }}(2.231 \AA)$ and the average $\mathrm{U}-\mathrm{N}_{\text {imine }}(2.612 \AA$ bond) lengths are also in the range of

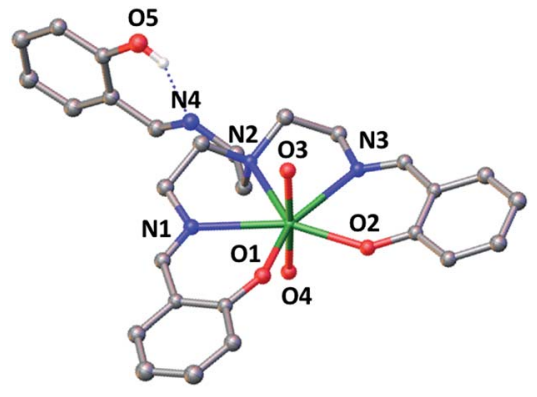

Fig. 1 Ellipsoid plot at 50\% probability of 2 (co-crystallised pyridine molecule and hydrogen atoms were omitted for clarity, $\mathrm{C}$ atoms are represented in grey, $\mathrm{O}$ in red, $\mathrm{N}$ in blue and $\mathrm{U}$ in green). Selected distances $(\AA) \cup(1)-O(1) 2.222(3), U(1)-O(2) 2.240(3), U(1)-O(3) 1.783(3)$, $\mathrm{U}(1)-\mathrm{O}(4)$ 1.787(3), $\mathrm{U}(1)-\mathrm{N}(1) 2.584(3), \mathrm{U}(1)-\mathrm{N}(2) 2.625(3), \mathrm{U}(1)-\mathrm{N}(3)$

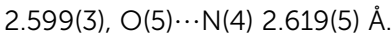

those found in other reported Schiff base complexes of $\operatorname{uranyl}(\mathrm{vI}){ }^{8 a, d, 9,15}$

In the attempt to reduce the uranyl(vi) complex 2 we added 1 eq. of decamethyl cobaltocene $\left(\mathrm{Cp}^{*}{ }_{2} \mathrm{Co}\right)$ to pyridine solutions of 2. The ${ }^{1} \mathrm{H}$ NMR spectrum of the resulting reaction mixture immediately after addition shows the presence of a large number of signals in the -45 to $45 \mathrm{ppm}$ range suggesting that a putative uranyl(v) intermediate complex undergoes rapid disproportionation (Fig. S4 $\dagger$ ). This suggests that the phenol arm protonates the more basic uranyl(v) (compared to uranyl(vi)) oxo group resulting in proton induced disproportionation.

In contrast, the uranyl $(\mathrm{v})$ complex $\left[\mathrm{UO}_{2}\right.$ (trensal)K]K, 3, is conveniently prepared in $70 \%$ yield from the salt metathesis reaction between $\mathrm{K}_{3}$ trensal and $\left[\left(\mathrm{UO}_{2} \mathrm{Py}_{5}\right)\left(\mathrm{KI}_{2} \mathrm{Py}_{2}\right)\right]_{n}$ in pyridine (Scheme 1).

The ${ }^{1} \mathrm{H}$ NMR spectrum of 3 in deuterated pyridine showed the presence of fluxional species with signals in the paramagnetic region ( -11 to $15 \mathrm{ppm})$ characteristic of $\mathrm{U}(\mathrm{v})$. Cooling down or heating up the NMR sample did not lead to a better resolution of the spectrum (Fig. S5 $\dagger$ ).

The addition of stoichiometric amounts of 2.2.2 cryptand $(4,7,13,16,21,24$-hexaoxa-1,10-diazabicyclo[8.8.8]hexacosane) to complex 3 resulted in a well resolved ${ }^{1} \mathrm{H}$ NMR spectrum (Fig. S6†). This suggests that fluxional potassium binding to the uranyl oxygen is the cause of the broad features in the ${ }^{1} \mathrm{H}$ NMR spectrum of 3 .

The complex $\left[\mathrm{UO}_{2}\right.$ (trensal)] [K(2.2.2crypt)][K(2.2.2crypt)], 4, was obtained analytically pure as a green solid in $62 \%$ yield. The solid-state structure of $\mathbf{4}$ was determined by X-ray diffraction

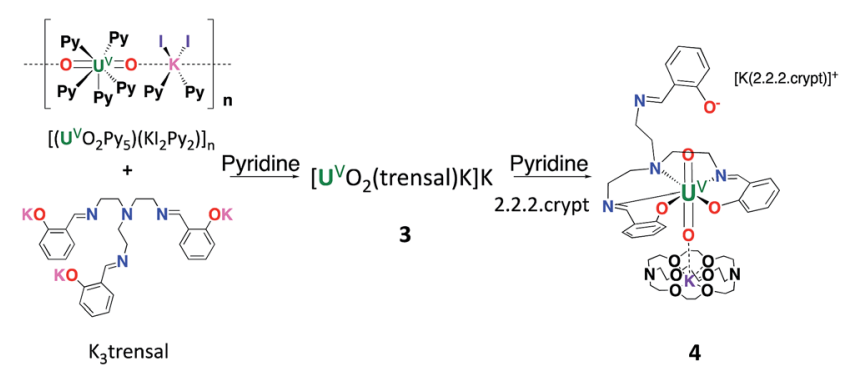

Scheme 1 Synthesis of the complexes 3 and 4 . 
studies and is presented in Fig. 2. The overall quality of the crystal structure of compound $\mathbf{4}$ is rather poor (very weakly diffracting sample) but its connectivity is well determined.

The coordination environment around the uranium centre is similar to that found in complex 2 . In 4 the uranium atom is heptacoordinated in a pentagonal bipyramidal coordination geometry. Five donor atoms of the trensal ligand (two oxygen and three nitrogen atoms) occupy the equatorial plane of the uranium ion, while the third arm of the trensal ${ }^{3-}$ ligand does not interact with any cation and one [K(cryptand)] cation is found as an isolated ion in the unit cell of 4 . The bipyramid axial positions in $\mathbf{4}$ are occupied by two oxo ligands with $\mathrm{U}-\mathrm{O}$ distances (1.824(15) and 1.865(16) ̊) significantly longer than those found in the uranyl(vi) complex 2 (1.785(3) $\AA$ ). These distances are in the range of those found in previously reported complexes of uranyl(v). ${ }^{\mathbf{1 3 a}, \boldsymbol{e}, \mathbf{1 3 f}}$

The ${ }^{1} \mathrm{H}$ NMR spectrum of $\mathbf{4}$ in pyridine shows the presence of 12 narrow signals in agreement with the presence of $\mathrm{C}_{2}$ symmetric solution species (Fig. S6†). This indicates that the molecular anionic fragment $\left[\mathrm{UO}_{2} \text { (trensal)] [K(2.2.2crypt) }\right]^{-}$ found in the $\mathrm{X}$-ray structure of $\mathbf{4}$ dissociates in pyridine solution and the $[\mathrm{K}(2.2 .2 \mathrm{crypt})]^{+}$cation is not bound to the uranyl(v) oxo group in pyridine solution.

The solid-state X-band EPR spectra measured at $298 \mathrm{~K}$ and $10 \mathrm{~K}$ revealed that the complex 3 is EPR silent.

In contrast, the solid-state X-band $(9.40 \mathrm{GHz})$ EPR spectrum of 4 shows an intense signal at $10 \mathrm{~K}$ with a fitted rhombic set of $g$-values $\left(g_{1}=2.44 ; g_{2}=1.10 ; g_{3}<0.6\right)$, confirming the presence of uranium in the oxidation state +5 (Fig. S29†). Notably, encapsulation of potassium enables us to obtain an EPR signal from the otherwise EPR silent complex 3. The likely presence of two potassium binding both uranyl(v) oxo groups results in a different electronic structure of $\mathbf{3}$ compared to $\mathbf{4}$ (where only one potassium cation is bound) which results in the absence of the EPR signal. ${ }^{13 e}$

Complex 4 is stable up to one month in the solid state and in pyridine and THF solutions. In order to assess the stability of these uranyl(v) complexes with respect to proton induced

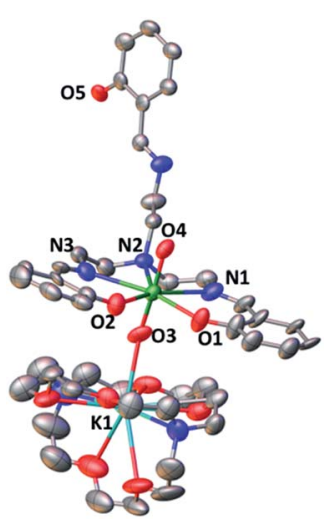

Fig. 2 Ellipsoid plot at $50 \%$ probability of the anion $\left[\mathrm{UO}_{2}\right.$ (trensal)] $[\mathrm{K}(2.2 .2 \mathrm{crypt})]^{-}$in $4\left(\mathrm{H}\right.$ and $[\mathrm{K}(2.2 .2 \mathrm{crypt})]^{+}$were omitted for clarity, C atoms are represented in grey, $\mathrm{O}$ in red, $\mathrm{N}$ in blue, $\mathrm{K}$ in light blue and $\mathrm{U}$ in green). Selected distances $(\AA) \cup(1)-O(3)$ 1.865(16), $U(1)-O(4)$ 1.824(15). disproportionation, we have investigated the reaction of $\mathbf{3}$ and 4 with protons. After addition of 1 eq. of $\mathrm{PyHCl}$ to complex 3, partial disproportionation of the uranyl(v) complex was observed by ${ }^{1} \mathrm{H}$ NMR spectroscopy. The addition of 2 eq. of $\mathrm{PyHCl}$ resulted in the complete disproportionation of the uranyl(v) to afford the uranyl(vi) complex 2 and unidentified U(Iv) products as indicated by ${ }^{1} \mathrm{H}$ NMR spectroscopy (Fig. S7†) and single crystal X-ray diffraction of the isolated crystal of the complex 2. The U(Iv) compounds formed in the disproportionation were identified as the product of the hydrolysis of the $[\mathrm{U}($ trensal $)] \mathrm{Cl}$ complex as confirmed by the ${ }^{1} \mathrm{H}$ NMR spectrum of a $1: 1: 2$ mixture of $\left[\mathrm{UO}_{2}(\right.$ Htrensal $\left.)\right],[\mathrm{U}($ trensal $)] \mathrm{X}(X=\mathrm{I}, \mathrm{Cl})$ and $\mathrm{H}_{2} \mathrm{O}$ (Fig. $\mathrm{S} 8 \dagger$ ).

On the other hand, addition of $\mathrm{PyHCl}$ to 4 initially resulted in the formation of NMR silent species, but after 3 days the ${ }^{1} \mathrm{H}$ NMR spectrum shows the formation of the same disproportionation products as those found in the reaction of 3 with 2 eq. of PyHCl (Fig. S9†).

\section{Iron binding to uranyl(v) complexes}

In view of the potential important role of iron binding in the abiotic reduction of uranyl(vi) as well as in the stabilization of uranyl(v) at iron mineral surfaces we have investigated the reactivity of complexes $\mathbf{1}$ and $\mathbf{3}$ with iron salts.

The reaction of 1 with $\mathrm{FeI}_{2}$ affords the trinuclear complex $\left[\left\{\mathrm{UO}_{2}(\text { trensal })\right\}_{2} \mathrm{Fe}\right], \mathbf{5}$, in $93 \%$ yield according to Scheme 2 .

The solid state structure of 5 (Fig. 3) shows the presence of a neutral trinuclear complex where two $\left[\mathrm{UO}_{2}(\right.$ trensal $\left.)\right]$ moieties are held together by a $\mathrm{Fe}(\mathrm{II})$ cation bound by two trensal $\mathrm{O}, \mathrm{N}$ donor atoms not involved in the coordination of the uranyl cation. Thus, the replacement of the potassium cation in $\mathbf{1}$ with a Fe(II) cation leads to formation of a trinuclear structure.

In order to prepare a trinuclear uranyl(v) analogue we allowed 5 to react with $\mathrm{Cp}_{2}{ }_{2} \mathrm{Co}$. The ${ }^{1} \mathrm{H}$ NMR spectrum after addition of 1 eq. of $\mathrm{Cp}_{2}{ }_{2} \mathrm{Co}$ to complex 5 revealed the formation of a complex reaction mixture. One of the products could be identified by X-ray diffraction studies, revealing the formation of the dinuclear heterobimetallic complex $\left[\mathrm{UO}_{2}(\right.$ trensal $\left.) \mathrm{Fe}(\mathrm{py})_{3}\right]$, 6. Addition of 2.5 eq. of $\mathrm{Cp}_{2}{ }_{2} \mathrm{Co}$ to a pyridine solution of 5 led to an intractable reaction mixture from which none of the components could be identified (Fig. S11c $\dagger$ ).

Complex 6 can be conveniently prepared in 81\% yield from the reaction of $\mathrm{FeI}_{2}$ with complex 3 in pyridine in a $1: 1$ ratio (Scheme 3).

The solid-state structure of $\mathbf{6}$, represented in Fig. 4, shows the presence of a neutral dinuclear complex where a $\left[\mathrm{U}^{\mathrm{V}} \mathrm{O}_{2}\right.$ (trensal)] dianion binds a $\mathrm{Fe}^{2+}$ cation through a $\mathrm{UO}_{2}{ }^{+} \ldots \mathrm{Fe}^{2+} \mathrm{CCI}$.

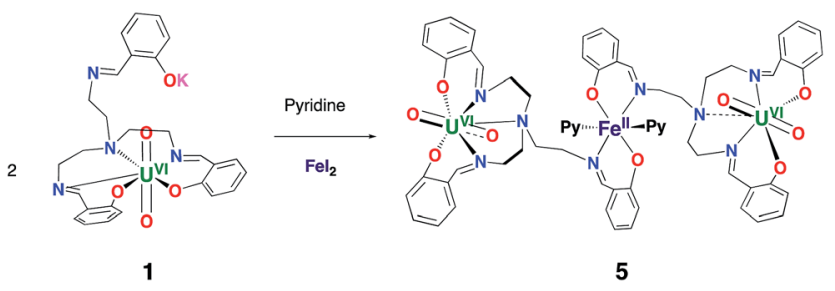

Scheme 2 Synthesis of $\left[\left(\mathrm{UO}_{2}(\text { trensal })\right)_{2} \mathrm{Fe}(\mathrm{Py})_{2}\right], 5$ 


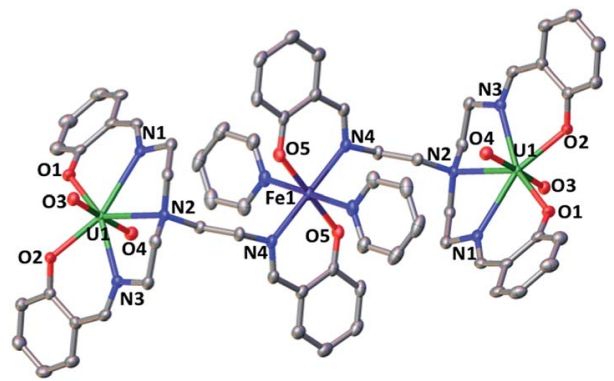

Fig. 3 Ellipsoid plot at $50 \%$ probability of 5 (co-crystallised pyridine molecule and $\mathrm{H}$ were omitted for clarity, $\mathrm{C}$ atoms are represented in grey, $\mathrm{O}$ in red, $\mathrm{N}$ in blue, $\mathrm{Fe}$ in dark blue and $\mathrm{U}$ in green). Selected distances (Å) $U(1)-O(1)$ 2.2321(18), $U(1)-O(2)$ 2.223(2), $U(1)-O(3)$ 1.7892(18), $\quad U(1)-O(4) \quad 1.7851(18), \quad U(1)-N(1) \quad 2.595(2), \quad U(1)-N(2)$ 2.604(3), U(1) $-\mathrm{N}(3)$ 2.558(2), $\mathrm{Fe}(1)-\mathrm{N}(4)$ 2.140(2), $\mathrm{Fe}(1)-\mathrm{O}(5) 2.0165(18)$

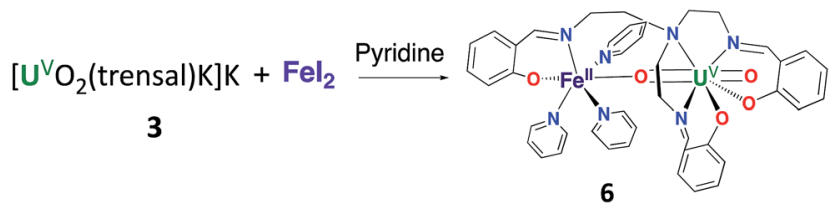

Scheme 3 Synthesis of $\left[\mathrm{UO}_{2}\right.$ (trensal) Fe(py) 3 ], 6

The $\mathrm{Fe}^{2+}$ cation is hexacoordinated, with a slightly distorted octahedral geometry, by two donor atoms of the trensal ${ }^{3-}$ ligand, one uranyl oxo group and three pyridine molecules. The uranium cation is heptacoordinate with a slightly distorted pentagonal bipyramid geometry, by two uranyl oxygen atoms and five donor atoms of the trensal ${ }^{3-}$ ligand in the equatorial plane. The mean $\mathrm{U}-\mathrm{O}$ bond lengths lie in the range of values typically observed for uranyl(v) complexes, ${ }^{1 a, 8 c, 13 a, e, 13 f, 14 f}$ with the $\mathrm{UO}_{2}{ }^{+} \cdots \mathrm{Fe}^{2+}$ interaction resulting in a slight lengthening of the bond (U1-O4 = $1.930(2) \AA$ and $\mathrm{U} 1-\mathrm{O} 3=1.837(3) \AA)$. The value of the $\mathrm{Fe}-\mathrm{O}$ bond length $(2.018(3) \AA)$ falls in the range of those found in the only two previously reported examples of uranyl(v) complexes presenting a cation-cation interaction with a $\mathrm{Fe}^{2+}$

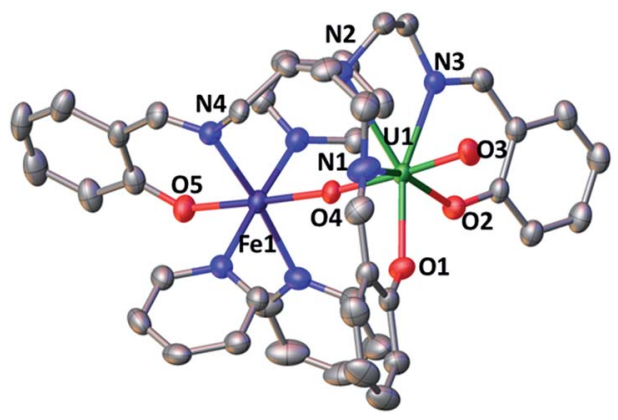

Fig. 4 Ellipsoid plot at 50\% probability of complex 6 (co-crystallised pyridine molecule and $\mathrm{H}$ were omitted for clarity, $\mathrm{C}$ atoms are represented in grey, $\mathrm{O}$ in red, $\mathrm{N}$ in blue, $\mathrm{Fe}$ in dark blue and $\mathrm{U}$ in green). Selected distances $(\AA) \cup(1)-O(1) 2.300(3), U(1)-O(2) 2.301(3), U(1)-$ $\mathrm{O}(3)$ 1.837(3), $U(1)-O(4)$ 1.930(2), $U(1)-N(1)$ 2.595(4), $U(1)-N(2)$ 2.715(3), $U(1)-N(3)$ 2.598(3), $\mathrm{Fe}(1)-\mathrm{N}(4)$ 2.147(3), $\mathrm{Fe}(1)-\mathrm{O}(5) 2.023(3)$, $\mathrm{Fe}(1)-\mathrm{O}(4) 2.018(3)$. cation $(1.946(4)-2.132(4) \AA) .{ }^{14 c, f}$ Similar Fe-O bond lengths ranging from 1.935(4) to 2.058(4) Å were reported for uranyl(vi) complexes bridged to $\mathrm{Fe}(\mathrm{III})$ via a hydroxo group. ${ }^{16}$

The ${ }^{1} \mathrm{H}$ NMR spectrum of 6 in pyridine shows the presence of 12 signals over a broad range of chemical shifts $(-30$ to +51 $\mathrm{ppm})$. The large shift of the ${ }^{1} \mathrm{H}$ NMR signals observed for 6 compared to complex 4 indicates that the $\mathrm{UO}_{2}{ }^{+} \cdots \mathrm{Fe}^{2+} \mathrm{CCI}$ is present in pyridine solution (Fig. S12 $\dagger$ ). The ESI/MS spectrum ( $\left\{\mathrm{UO}_{2}(\right.$ trensal $\left.\left.) \mathrm{Fe}(\mathrm{Py})^{+}\right\}: m / z=859.83\right)$ of 6 also indicates the presence of the heterobimetallic complex in pyridine solution (Fig. S26†).

The stability and reactivity of 6 were then investigated and compared with those found for $\mathbf{3}$ and $\mathbf{4}$ in order to elucidate the effect of the $\mathrm{Fe}^{2+}$ ion. The addition of 1 eq. of PyHCl to a solution of 6 in pyridine results in the partial disproportionation of the uranyl(v) complex (Scheme 4) with a 2:1 ratio of 6 to the disproportionation product $\left[\mathrm{UO}_{2}(\right.$ trensal $) \mathrm{Fe}(\mathrm{py})_{3} \mathrm{U}$ (trensal $\left.)\right] \mathrm{Cl}$ $7 \mathbf{b}$ (Fig. S20 $\dagger$ ). The addition of 2 equivalents of PyHCl to 6 led to the complete disappearance of the signals of complex 6 in the ${ }^{1} \mathrm{H}$ NMR spectrum (Fig. S13 $\dagger$ ) and to an increased intensity of the signals assigned to $\mathbf{7 b}$. The presence of the uranyl(vi) complex $\left[\mathrm{UO}_{2}(\right.$ Htrensal $\left.)\right]$ as the second disproportionation product was also identified by ${ }^{1} \mathrm{H}$ NMR spectroscopy.

However, in both cases the disproportionation was not complete. Notably, the trinuclear cation-cation complex $\mathbf{7 b}$ contains unreacted uranyl(v) (Scheme 4).

The formation of the $\left[\mathrm{UO}_{2}(\mathrm{Htrensal})\right]$ by-product prevented the synthesis of $\mathbf{7 b}$ from the reaction of $\mathbf{6}$ with $\mathrm{PyHCl}$ (Scheme 4).

However, the iodide analogue $\left[\mathrm{UO}_{2}(\right.$ trensal $) \mathrm{Fe}(\text { py })_{3^{-}}$ $\mathrm{U}$ (trensal)]I, 7 was prepared in $80 \%$ yield from the reaction of complex 6 with 1 eq. of the [U(trensal)]I complex in pyridine (Scheme 4). This complex is a rare example of an actinidefunctionalized uranyl complex and only the third example of a uranyl(v) complex presenting a CCI between the uranyl(v) oxo group and a U(Iv) cation., ${ }^{9,13 l}$

The structure of complex 7 (Fig. 5) shows the presence of a cationic trinuclear complex built via CCI between the U(Iv) center from the $[\mathrm{U}(\text { trensal })]^{+}$complex and the oxo group of the uranyl(v) $\left[\mathrm{UO}_{2}(\right.$ trensal $\left.) \mathrm{Fe}(\text { py })_{3}\right]$ fragment. The three metal ions adopt a close to linear arrangement with a $\mathrm{Fe}-\mathrm{O}-\mathrm{U}$ angle of $170.3(3)^{\circ}$ and a $\mathrm{U}-\mathrm{O}-\mathrm{U}$ angle of $171.2(3)^{\circ}$. The $\mathrm{U}=\mathrm{O}$ bond distance for the uranyl(v) oxo group bound to the $\mathrm{Fe}^{2+}$ remains unchanged at 1.922(6) ^ compared to complex 6, but a significant lengthening of the $\mathrm{U}=\mathrm{O}$ bond is observed upon binding of the $\mathrm{U}(\mathrm{rv})$ cation in 7 (1.960(6) $\AA$ ). The $\mathrm{UO}_{2}^{+}{ }^{+} \cdot \mathrm{U}(\mathrm{rv})$ distance

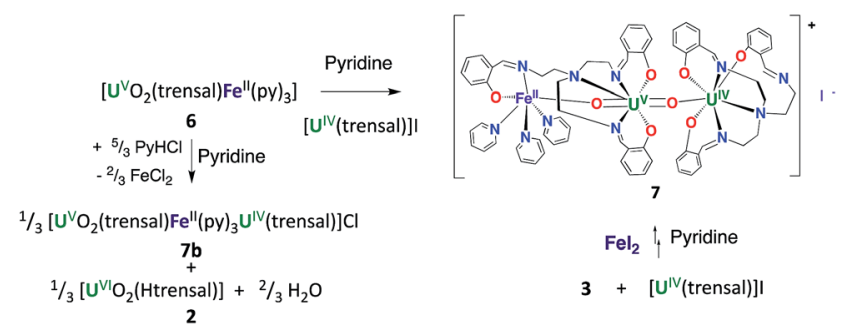

Scheme 4 Addition of $\mathrm{PyHCl}$ to the complex 6 and synthesis of 7. 


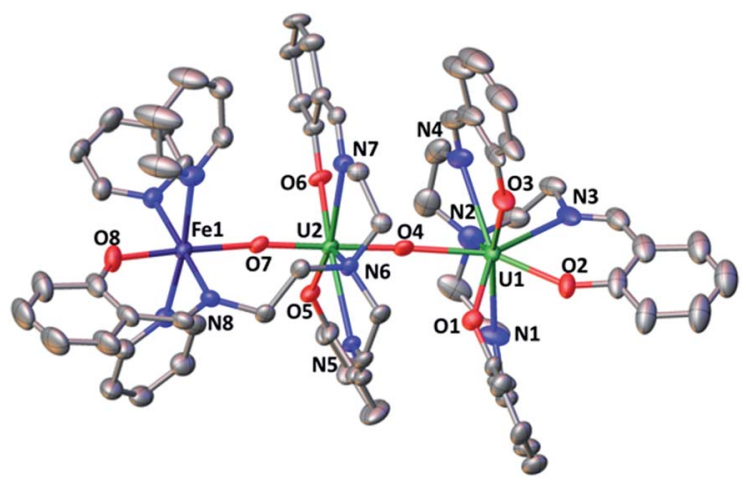

Fig. 5 Ellipsoid plot at $50 \%$ probability of the cation $\left[\mathrm{UO}_{2}\right.$ (trensal) $\mathrm{Fe}\left(\text { py) }{ }_{3} \mathrm{U} \text { (trensal) }\right]^{+}$in 7 (co-crystallized pyridine molecule and $\mathrm{H}$ were omitted for clarity, $\mathrm{C}$ atoms are represented in grey, $\mathrm{O}$ in red, $\mathrm{N}$ in blue, $\mathrm{Fe}$ in dark blue and $U$ in green). Selected distances $(\AA) U(1)-O(2)$ 2.216(6), $U(1)-O(4) 2.317(6), U(1)-N(2) 2.713(8) U(2)-O(4)$ 1.960(6), $\mathrm{U}(2)-\mathrm{O}(5)$ 2.267(6), $\mathrm{U}(2)-\mathrm{O}(7)$ 1.922(6), U(2)-N(6) 2.653(7), $\mathrm{Fe}(1)-\mathrm{O}(7)$ 2.144(6), $\mathrm{Fe}(1)-\mathrm{O}(8) 2.033(6), \mathrm{Fe}(1)-\mathrm{N}(8) 2.159(7)$.

(2.317(6) $\AA$ ) is comparable to those found in the only two other complexes reported to have a $\mathrm{UO}_{2}{ }^{+} \ldots \mathrm{U}(\mathrm{Iv}) \mathrm{CCI}(2.198(13)$ and $2.245(3) \AA) .9,131$

The $\mathrm{UO}_{2}{ }^{+} \cdots \mathrm{Fe}^{2+}$ distance $(2.144(6) \AA)$ is slightly longer than in 6 but is in the range of those found in the two previously reported complexes presenting a $\mathrm{UO}_{2}{ }^{+} \cdots \mathrm{Fe}^{2+}$ interaction (1.946(4) $\mathrm{A}-2.132(4) \AA) .{ }^{14 c_{r} f}$

These results indicate that the presence of $\mathrm{Fe}^{2+}$ increases the stability of uranyl(v) in $\mathbf{6}$ with respect to proton induced disproportionation. Notably the addition of 2 eq. of $\mathrm{PyHCl}$ led to full disproportionation of the complexes $\mathbf{3}$ and $\mathbf{4}$ while it resulted only in the partial disproportionation of $\mathbf{6}$ and the formation of $\left[\mathrm{UO}_{2}(\right.$ Htrensal $\left.)\right]$ and of the $\mathrm{Fe}-\mathrm{U}(\mathrm{v})-\mathrm{U}(\mathrm{Iv})$ trimer. The addition of five equivalents of pyridinium chloride is required for the full disproportionation of complex 6 to occur affording the same uranyl(vI) and U(Iv) diproportionation products as observed after addition of acid to 3 . This indicates that the iron bound uranyl(v) complex 6 displays an increased stability towards the proton induced disproportionation compared to the potassium bound uranyl(v) complexes 3 and $\mathbf{4}$ (Fig. S14 $\dagger$ ).

The binding of U(Iv) to the uranyl(v) oxo group was previously reported to promote partial disproportionation and formation of multimetallic U(Iv)-U(v) oxo-bridged complexes. ${ }^{9}$ The stabilizing effect of $\mathrm{Fe}^{2+}$ compared to $\mathrm{U}^{4+}$ can be explained in terms of the lower Lewis acidity of $\mathrm{Fe}^{2+}$ compared to $\mathrm{U}^{4+}$. This results in the formation of stable $\mathrm{UO}_{2}{ }^{+} \cdots \mathrm{Fe}^{2+}$ adducts where the uranyl oxo group becomes less accessible to protonation by the Brønsted acid $\mathrm{H}^{+}$. In contrast, complex 7 is stable in pyridine solution over one month period. ${ }^{1} \mathrm{H}$ NMR studies show that the addition of [U(trensal)] I to complex $\mathbf{3}$ also leads to the formation of a stable unidentified compound (Fig. S15 $\dagger$ ). The subsequent addition of $\mathrm{FeI}_{2}$ to this compound led to the formation of complex 7. These results suggest that stable $\mathrm{U}(\mathrm{Iv})-\mathrm{U}(\mathrm{v})$ complexes also form in the absence of iron bound to uranyl(v) oxo group. However, the formation of these compounds is not observed during the addition of PyHCl to 3, which undergoes complete disproportionation after the addition of 2 eq. of
PyHCl. Moreover, the addition of 2 eq. of $\mathrm{PyHCl}$ to the U(Iv)-U(v) adduct results in full disproportionation, as indicated by the ${ }^{1} \mathrm{H}$ NMR spectrum, suggesting that the binding of U(Iv) to the uranyl(v) oxo does not lead to increased stability (Fig. S15 $\dagger$ ). This further confirms the stabilizing role of Fe(II) binding with respect to proton induced disproportionation of uranyl(v).

The ${ }^{1} \mathrm{H}$ NMR spectrum of 7 in pyridine shows the presence of 45 signals over a large range of chemical shifts $(-35$ to +53 $\mathrm{ppm}$ ) in agreement with the presence of the trimeric complex 7 in solution. (Fig. S16†). Additionally, the ESI/MS spectrum of 7 in pyridine solution $\left\{\left(\mathrm{UO}_{2}(\right.\right.$ trensal $\left.) \mathrm{Fe}_{3} \mathrm{U}(\text { trensal })^{+}\right\} \mathrm{m} / \mathrm{z}=$ 1474.42) indicated that the complex 7 retains its trinuclear structure in the pyridine solution (Fig. S27†).

The addition of 1 eq. of pyridinium chloride to 7 results in partial disproportionation with a $3: 1$ ratio of complex 7 to the disproportionation products as shown by ${ }^{1} \mathrm{H}$ NMR spectroscopy (Fig. S17†). The complete disproportionation of complex 7 requires the addition of $4 \mathrm{eq}$. of $\mathrm{PyHCl}$. The coordination of $\mathrm{U}(\mathrm{Iv})$ does not increase the stability of the uranyl(v) species in 7 with respect to 6 .

In view of the increased stability of 7 and 6 compared to 3 towards proton induced disproportionation, we set out to investigate how the coordination of a second $\mathrm{Fe}^{2+}$ cation to complex 6 would affect the structure and reactivity of the $\mathrm{U}(\mathrm{v})$ centre.

The ${ }^{1} \mathrm{H}$ NMR of the reaction mixture resulting from the addition of 0.5 equivalents of iron(II) iodide to 6 in pyridine indicated the formation of a new species (Fig. S18 $\dagger$ ). X-ray quality crystals of $\left[\left(\mathrm{UO}_{2}(\text { trensal }) \mathrm{Fe}(\mathrm{py})_{3}\right)_{2} \mathrm{Fe}(\mathrm{py})_{3}\right] \mathrm{I}_{2}, \mathbf{8}$, were obtained in $65 \%$ yield from this reaction (Scheme 5). The solidstate structure (Fig. 6) of 8 shows the presence of a pentametallic structure where a $\mathrm{Fe}(\mathrm{Py})_{3}$ moiety bridges two iron-bound uranyl(v) $\left[\mathrm{UO}_{2}(\text { trensal)Fe(py) })_{3}\right]$ moieties. Overall, this results in the presence of $\mathrm{UO}_{2}{ }^{+} \cdots \mathrm{Fe}^{2+}$ CCIs for both uranyl(v) oxo-groups. The central $\mathrm{Fe}^{2+}$ cation is penta-coordinated by one oxo atom from each of the two uranyl(v) groups and three pyridine molecules. The mean $\mathrm{Fe}(2)-\mathrm{O}$ (oxo) bond lengths is $1.988 \AA$. The $\left[\mathrm{UO}_{2}(\right.$ trensal $\left.) \mathrm{Fe}(\mathrm{py})_{3}\right]$ moieties of the crystal structure possess the same geometry found in the mononuclear complex $\mathbf{6}$, but the additional uranyl-iron interaction results in a slight lengthening of the $\mathrm{UO}_{2}{ }^{+} \ldots \mathrm{Fe}^{2+}$ bonds compared to 6 (2.061(4) $\AA$ vs. 2.018(3) $\mathrm{\AA})$. The arrangement of the 5 metal ions is not linear, with a $\mathrm{Fe}_{1} \widehat{\mathrm{Fe}_{2}} \mathrm{Fe}_{3}$ angle of $136^{\circ}$.

The ESI/MS spectrum of 8 (Fig. S28†) did not show the presence of a pentanuclear architecture in pyridine solution but showed only the peaks corresponding to the trinuclear $\{\mathrm{Fe}-\mathrm{U}-$ $\mathrm{Fe}\}$ and dinuclear $\{\mathrm{Fe}-\mathrm{U}\}$ complexes. The addition of 1 eq. of the complex $\left[\mathrm{UO}_{2}(\right.$ trensal $\left.) \mathrm{Fe}(\mathrm{py})_{3}\right]$ to a solution of $\mathbf{8}$ in pyridine resulted only in a slight broadening of the ${ }^{1} \mathrm{H}$ NMR signals of 8 suggesting the presence in solution of a fast exchange between the $\left.\left[\mathrm{UO}_{2} \text { (trensal)Fe(py) }\right)_{3}\right]$ moiety and 8 (Fig. S19†).

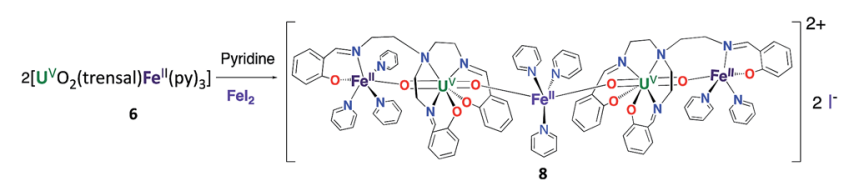

Scheme 5 Synthesis of $\left.\left[\left(\mathrm{UO}_{2}(\text { trensal }) \mathrm{Fe}(\mathrm{py})_{3}\right)_{2} \mathrm{Fe}(\mathrm{py})_{3}\right]\right]_{2}, 8$ 


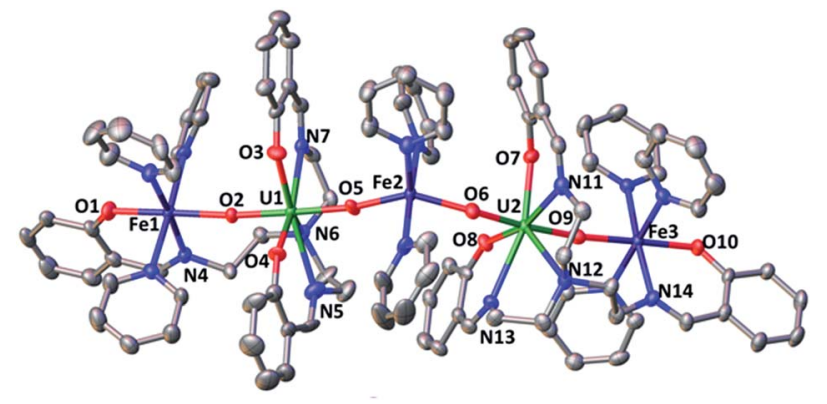

Fig. 6 Molecular structure of the dication $\left[\left\{\cup_{2} \text { (trensal)Fe(py }\right)_{3}\right\}$ $\left.{ }_{2} \mathrm{Fe}(\mathrm{py})_{3}\right]^{2+}$ in $8(\mathrm{H}$ atoms were omitted for clarity, $\mathrm{C}$ atoms are represented in grey, $\mathrm{O}$ in red, Fe in dark blue, $\mathrm{N}$ in blue, I in purple and $\mathrm{U}$ in green). Selected distances U1-O2 $=1.920$ (4) A, U1-O5 = 1.935 (4) $\AA$, U2-O6 = 1.927 (4) $\AA$ and U2-O9=1.927 (5) Å.

The labile binding of the central $\mathrm{Fe}(\mathrm{Py})_{3}{ }^{2+}$ cation in 8 does not lead to an increased stability of $\mathbf{8}$ towards proton induced disproportionation compared to 6 . Notably, the ${ }^{1} \mathrm{H}$ NMR indicated a 2:1 ratio between the starting complex 8 and the disproportionation products upon addition of 1 eq. of $\mathrm{H}^{+}$per uranyl(v) which is identical to the ratio observed for the complex 6 (Fig. S20†).

\section{Redox reactivity}

Iron binding to the uranyl(v) oxo is anticipated to have an important effect on its redox reactivity. Moreover, it has been suggested that iron binding at mica surfaces leads to the stabilization of uranyl(v) intermediates but the effect of iron binding on the redox properties of isolated uranyl(v) complexes has not been investigated.

At first, we explored the chemical oxidation of uranyl(v) by $\mathrm{Fe}^{3+}$. The reaction of 3 with 1 eq. $\mathrm{FeCl}_{3}$ leads to the oxidation of the uranium center (Fig. S21 $\dagger$ ) and to the formation of the uranyl(VI)-Fe(II) complex $2\left[\left(\mathrm{UO}_{2}(\text { trensal })\right)_{2} \mathrm{Fe}\right]$ as identified by $\mathrm{X}$ ray diffraction crystallography and ${ }^{1} \mathrm{H}$ NMR spectroscopy. The oxidation of uranyl(v) complex to uranyl(vi) by Fe(III) is explained in terms of the respective redox potential $(\mathrm{Fe}(\mathrm{III}) / \mathrm{Fe}(\mathrm{II})=0.0 \mathrm{~V}$; $\mathrm{UO}_{2}{ }^{2+} / \mathrm{UO}_{2}{ }^{+}=-1.6$ vs. $\left.\mathrm{V}\left(\mathrm{Fc} / \mathrm{Fc}^{+}\right)\right)$.

In order to probe the possibility of obtaining a uranyl(v)Fe(III) complex we explored the reactivity of 3 and 6 with increasingly electron-rich $\mathrm{FeLCl}_{n}$ complexes ( $\mathrm{L}=$ tpa and tdmba); tpa $=($ tris(pyridin-2-ylmethyl)amine $)$ and $\mathrm{H}_{3}$ tdmba $=$ (tris-(2-hydroxy-3,5-dimethylbenzyl)amine). The reaction of 6 with $\left[\mathrm{Fe}(\mathrm{tpa}) \mathrm{Cl}_{3}\right]$ led to the oxidation of uranyl(v) to uranyl(vi) with concomitant formation of $\left[\mathrm{Fe}(\mathrm{tpa}) \mathrm{Cl}_{2}\right.$ ] (as shown by X-ray diffraction studies and ${ }^{1} \mathrm{H}$ NMR spectroscopy). The reaction of 6 with the neutral Fe(III) complex [Fe(tdmba)] did not result in any change observable in the ${ }^{1} \mathrm{H}$ NMR spectrum of 6 (Fig. S23 †) indicating that the $\mathrm{Fe}(\mathrm{III})$ cation in $[\mathrm{Fe}(\mathrm{tdmba})]$ does not form CCIs with the uranyl(v) oxo group but does not oxidize the uranyl(v) either. In contrast, when complex 3 is reacted with [Fe(tdmba)], ${ }^{1} \mathrm{H}$ NMR spectroscopy indicated that a redox reaction occurs yielding uranyl(VI) and Fe(II) species (Fig. S24 $\dagger$ ). These results are in agreement with the reported influence of chelating agents on the reoxidation by $\mathrm{Fe}(\mathrm{III})$ of biogenic products of uranyl(vi) reduction. ${ }^{17}$

These results suggest that the presence of $\mathrm{UO}_{2}{ }^{+} \cdots \mathrm{Fe}^{2+} \mathrm{CCI}$ stabilizes the uranyl(v) oxidation state with respect to the oxidation. In order to further probe the effect of iron binding on the redox properties of $\operatorname{uranyl}(\mathrm{v})$ species we performed comparative cyclic voltammetry studies of complexes 1, 2, 5, 6 and 8 (Fig. 6 and SCV1-SCV4†). The voltammogram of 1 in pyridine (Fig SCV1 $\dagger$ ) shows an irreversible redox event at $-1.75 \mathrm{~V}$, but when the voltammogram of 1 is measured in the presence of the cryptand a reversible redox event assigned to the $\mathrm{U}(\mathrm{vI}) / \mathrm{U}(\mathrm{v})$ couple is observed at $E_{1 / 2}=-1.69 \mathrm{~V} v$ s. Fc/Fc ${ }^{+}$(Fig. 7, green curve). The voltammogram of the protonated uranyl(v) complex 2 also shows the presence of a reversible redox event at $E_{1 / 2}=-1.66 \mathrm{~V} v s . \mathrm{Fc} / \mathrm{Fc}^{+}$assigned to the $\mathrm{U}(\mathrm{vI}) / \mathrm{U}(\mathrm{v})$ couple. These values compare well with the values previously measured in pyridine for other uranyl(v) complexes of tetradentate $\left(E_{1 / 2}=\right.$ $-1.61 \mathrm{~V}$ or $-1.67 \mathrm{~V}$ vs. $\left.\mathrm{Fc} / \mathrm{Fc}^{+}\right)^{15 a, 13 e}$ and pentadentate Schiff bases $\left(E_{1 / 2}=-1.58 \mathrm{~V}\right.$ vs. $\left.\mathrm{Fc} / \mathrm{Fc}^{+}\right) .{ }^{18} \mathrm{~A}$ second irreversible redox event is observed at $E_{1 / 2}=-2.47 \mathrm{~V} v s$. $\mathrm{Fc} / \mathrm{Fc}^{+}$for complex 2, but not for complex 1. This event is consistent with the reduction of the metal centre (values of redox potential ranging from -2.02 to $-2.88 \mathrm{~V} v s$. $\mathrm{Fc} / \mathrm{Fc}^{+}$were previously assigned to the $\mathrm{U}(\mathrm{v}) / \mathrm{U}(\mathrm{Iv})$ couple $\left.^{12 a}\right)$. The possibility that this event could be related to the reduction of the Schiff base ligand is unlikely since this feature is absent from the voltammograms of the $\mathrm{H}_{3}$ trensal, $\mathrm{K}_{3}$ trensal ligands and of the complex 1. Moreover, the shift of the $\mathrm{U}(\mathrm{v}) / \mathrm{U}(\mathrm{Iv})$ couple to a more positive potential in complex 2 could be explained by the presence of a proton on the complex.

Similar redox events are observed in the voltammogram of complex 6 in addition to the quasi-reversible wave at $E_{1 / 2}=0.0 \mathrm{~V}$ vs. $\mathrm{Fc} / \mathrm{Fc}^{+}$, assigned to the $\mathrm{Fe}(\mathrm{III}) / \mathrm{Fe}(\mathrm{II})$ couple. However, the $\mathrm{U}(\mathrm{vI}) / \mathrm{U}(\mathrm{v})$ reduction process is found at $-1.03 \mathrm{~V} v s . \mathrm{Fc} / \mathrm{Fc}^{+}$in the voltammogram of 6 and the second reduction event occurs at $E_{1 / 2}=-2.7 \mathrm{~V} v s . \mathrm{Fc} / \mathrm{Fc}^{+}$demonstrating that the range of stability of the uranyl(v) species is significantly extended compared to complex 2 as a result of Fe(II) binding. Both reduction and oxidation of the uranyl(v) cation are more difficult in the

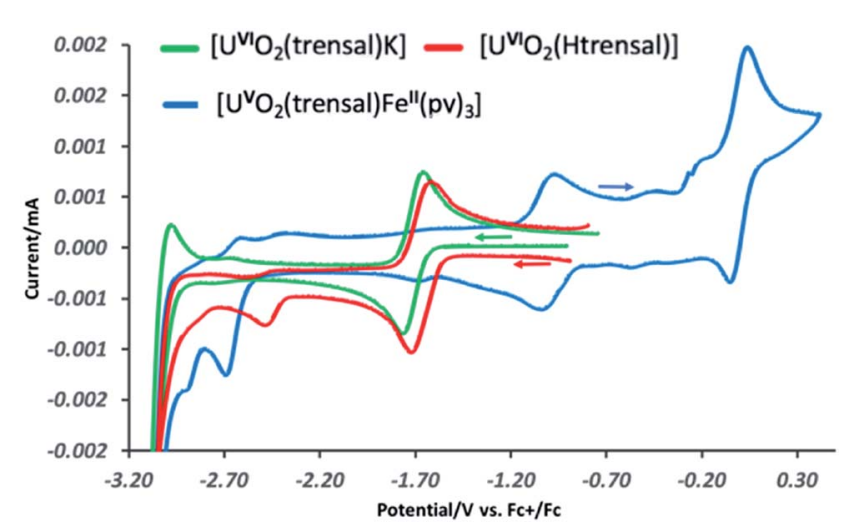

Fig. 7 Room temperature cyclic voltammograms of $4 \mathrm{mM}$ pyridine solutions of $\left[\mathrm{U}^{\mathrm{V} \mathrm{O}} \mathrm{O}_{2}\right.$ (trensal) $\left.\mathrm{K}\right] 1$ in the presence of 1 eq. of cryptand (green), of $\left[\mathrm{U}^{\mathrm{VI}} \mathrm{O}_{2}\left(\mathrm{H}\right.\right.$ trensal)] 2 (red) and of $\left[\mathrm{U}^{\vee} \mathrm{O}_{2}\right.$ (trensal) Fe $\left.{ }^{\prime \prime}(\text { py) })_{3}\right] 6$ (blue) recorded in $0.1 \mathrm{M}\left[\mathrm{Bu}_{4} \mathrm{~N}\right]\left[\mathrm{PF}_{6}\right]$ at $100 \mathrm{mV} \mathrm{s}^{-1}$ scan rate, $\mathrm{Cp}_{2} \mathrm{Fe} /$ $\mathrm{Cp}_{2} \mathrm{Fe}^{+}\left(\mathrm{Fc} / \mathrm{Fc}^{+}\right)$corrected. 
presence of $\mathrm{Fe}(\mathrm{II})$. No additional redox stabilisation was observed upon addition of two or more equivalents of $\mathrm{Fe}$ (II) to complex 6 as indicated by the voltammogram of complex 8 (Fig. SCV4 $\dagger$ ). This is probably due to the labile binding of the second $\mathrm{Fe}(\mathrm{II})$ cation to the uranyl(v) oxo group in pyridine.

Moreover, in the voltammogram of complex 5 (Fig. SCV2 $\dagger$ ) the redox event assigned to the $\mathrm{U}(\mathrm{vI}) / \mathrm{U}(\mathrm{v})$ couple is found at $E_{1 / 2}$ $=-1.66 \mathrm{~V} v s . \mathrm{Fc} / \mathrm{Fc}^{+}$as in complexes 1 and 2 in spite of the presence of a $\mathrm{Fe}(\mathrm{II})$ ion bound through the Schiff base acting as a bridging ligand. These results indicate that cation-cation interaction between the uranyl(v) oxygen and the $\mathrm{Fe}^{2+}$ is essential for the stabilization of $\mathrm{U}(\mathrm{v})$ while the presence of a Fe(II) bound through the ligand has no significant effect on the redox properties of uranyl(v).

\section{Conclusions}

In conclusion the tripodal heptadentate Schiff base trensal ${ }^{3-}$ ligand allowed the synthesis and characterization of uranyl(v) complexes presenting $\mathrm{UO}_{2}{ }^{+} \cdots \mathrm{K}^{+}$or $\mathrm{UO}_{2}{ }^{+} \cdots \mathrm{Fe}^{2+}$ cation-cation interactions. The reported uranyl(v) complexes show similar stability in pyridine solution, but the presence of $\mathrm{Fe}^{2+}$ bound to the uranyl(v) oxygen leads to increased stability with respect to proton induced disproportionation. A stable $\mathrm{Fe}^{2+}-\mathrm{UO}_{2}{ }^{+}-\mathrm{U}^{4+}$ intermediate (7b) containing both $\mathrm{UO}_{2}{ }^{+} \cdots \mathrm{Fe}^{2+}$ and $\mathrm{UO}_{2}{ }^{+} \cdots \mathrm{U}^{4+}$ cation-cation interactions formed upon addition of 2 eq. of PyHCl to the iron bound uranyl(v) complex (6). In contrast, the addition of 2 eq. of $\mathrm{PyHCl}$ to the potassium bound uranyl(v) complexes (3 and 4 ) resulted in the immediate formation of $\mathrm{U}(\mathrm{IV})$ and $\mathrm{UO}_{2}{ }^{2+}$ complexes. The $\mathrm{UO}_{2}{ }^{+} \cdots \mathrm{Fe}^{2+}$ (6) complex reacts with an additional $\mathrm{Fe}^{2+}$ cation leading to the formation of a pentanuclear $\mathrm{Fe}^{2+}-\mathrm{UO}_{2}{ }^{+}-\mathrm{Fe}^{2+}-\mathrm{UO}_{2}{ }^{+}-\mathrm{Fe}^{2+}$ complex (8) but the additional $\mathrm{Fe}^{2+}-\mathrm{UO}_{2}{ }^{+}$cation-cation interactions do not lead to increased stability. Redox reactivity and cyclic voltammetry studies also show an increased range of stability of the uranyl(v) species in the presence of $\mathrm{Fe}^{2+}$ with respect both to oxidation and reduction reactions, while the presence of a proton in the uranyl(vi) complex (2) results in a smaller stability range for the uranyl(v) species. Cyclic voltammetry studies also show that the presence of a $\mathrm{Fe}^{2+}$ cation bound only through one trensal ${ }^{3-}$ arm in the trinuclear complex $\left[\left\{\mathrm{UO}_{2}(\text { trensal })\right\}_{2} \mathrm{Fe}\right], \mathbf{5}$ does not lead to increased redox stability of the uranyl(v) demonstrating the important role of $\mathrm{UO}_{2}^{+} \cdots \mathrm{Fe}^{2+}$ cation-cation interactions in increasing the stability of uranyl(v). These results provide an important insight into the role that iron binding may play in stabilizing uranyl(v) species in the environmental mineralmediated reduction of uranium(vi).

\section{Conflicts of interest}

There are no conflicts to declare.

\section{Acknowledgements}

We thank Dr F. Fadaei Tirani for her contribution to the X-ray single crystal structure data collection and analyses. We thank Dr Euro Solari for elemental analysis, Dr A. Sienkiewicz and L.
Barluzzi for EPR data collection and L. Chatelain for preliminary experiments. We thank Prof. R. Bernier-Latmani for useful discussions. This work was supported by the Ecole Polytechnique Fédérale de Lausanne (EPFL) and by the Swiss National Science Foundation grant (number CR23I2_16645).

\section{Notes and references}

1 (a) P. L. Arnold, J. B. Love and D. Patel, Coord. Chem. Rev., 2009, 253, 1973-1978; (b) L. S. Natrajan, A. N. Swinburne, M. B. Andrews, S. Randall and S. L. Heath, Coord. Chem. Rev., 2014, 266, 171-193; (c) H. Steele and R. J. Taylor, Inorg. Chem., 2007, 46, 6311-6318; (d) J. C. Renshaw, L. J. C. Butchins, F. R. Livens, I. May, J. M. Charnock and J. R. Lloyd, Environ. Sci. Technol., 2005, 39, 5657-5660; (e) E. S. Ilton, A. Haiduc, C. L. Cahill and A. R. Felmy, Inorg. Chem., 2005, 44, 2986-2988.

2 (a) K. Yuan, E. S. Ilton, M. R. Antonio, Z. R. Li, P. J. Cook and U. Becker, Environ. Sci. Technol., 2015, 49, 6206-6213; (b) E. S. Ilton, J.-F. Boily, E. C. Buck, F. N. Skomurski, K. M. Rosso, C. L. Cahill, J. R. Bargar and A. R. Felmy, Environ. Sci. Technol., 2010, 44, 170-176; (c) F. N. Skomurski, E. S. Ilton, M. H. Engelhard, B. W. Arey and K. M. Rosso, Geochim. Cosmochim. Acta, 2011, 75, 7277-7290.

3 I. Pidchenko, K. O. Kvashnina, T. Yokosawa, N. Finck, S. Bahl, D. Schild, R. Polly, E. Bohnert, A. Rossberg, J. Gottlicher, K. Dardenne, J. Rothe, T. Schafer, H. Geckeis and T. Vitova, Environ. Sci. Technol., 2017, 51, 2217-2225.

4 (a) E. S. Ilton, J. S. L. Pacheco, J. R. Bargar, Z. Shi, J. Liu, L. Kovarik, M. H. Engelhard and A. R. Felmy, Environ. Sci. Technol., 2012, 46, 9428-9436; (b) H. E. Roberts, K. Morris, G. T. W. Law, J. F. W. Mosselmans, P. Bots, K. Kvashnina and S. Shaw, Environ. Sci. Technol. Lett., 2017, 4, 421-426.

5 L. R. Morss, N. M. Edelstein and J. Fuger, The Chemistry of the Actinide and Transactinide Elements, Springer, Dordrecht, 2006.

6 N. N. Krot and M. S. Grigoriev, Russ. Chem. Rev., 2004, 73, 89100.

7 (a) M. Sundararajan, A. J. Campbell and I. H. Hillier, J. Phys. Chem. A, 2008, 112, 4451-4457; (b) V. Mougel, B. Biswas, J. Pecaut and M. Mazzanti, Chem. Commun., 2010, 46, 8648-8650.

8 (a) M. B. Jones and A. J. Gaunt, Chem. Rev., 2013, 113, 11371198; (b) V. Mougel, P. Horeglad, G. Nocton, J. Pecaut and M. Mazzanti, Chem.-Eur. J., 2010, 16, 14365-14377; (c) L. Chatelain, V. Mougel, J. Pecaut and M. Mazzanti, Chem. Sci., 2012, 3, 1075-1079; (d) V. Mougel, P. Horeglad, G. Nocton, J. Pecaut and M. Mazzanti, Angew. Chem., Int. Ed. Engl., 2009, 48, 8477-8480; (e) G. Nocton, P. Horeglad, J. Pécaut and M. Mazzanti, J. Am. Chem. Soc., 2008, 130, 16633-16645; $(f)$ F. Burdet, J. Pecaut and M. Mazzanti, J. Am. Chem. Soc., 2006, 128, 16512-16513.

9 V. Mougel, J. Pecaut and M. Mazzanti, Chem. Commun., 2012, 48, 868-870.

10 (a) P. L. Arnold, N. A. Potter, N. Magnani, C. Apostolidis, J. C. Griveau, E. Colineau, A. Morgenstern, R. Caciuffo and 
J. B. Love, Inorg. Chem., 2010, 49, 5341-5343; (b) J. L. Brown, G. Wu and T. W. Hayton, J. Am. Chem. Soc., 2010, 132, 72487249; (c) D. D. Schnaars, G. Wu and T. W. Hayton, Inorg. Chem., 2011, 50, 4695-4697; (d) T. W. Hayton and G. Wu, Inorg. Chem., 2009, 48, 3065-3072.

11 D. D. Schnaars, G. Wu and T. W. Hayton, J. Am. Chem. Soc., 2009, 131, 17532-17533.

12 (a) J. R. Pankhurst, N. L. Bell, M. Zegke, L. N. Platts, C. A. Lamfsus, L. Maron, L. S. Natrajan, S. Sproules, P. L. Arnold and J. B. Love, Chem. Sci., 2017, 8, 108-116; (b) N. L. Bell, B. Shaw, P. L. Arnold and J. B. Love, J. Am. Chem. Soc., 2018, 140, 3378-3384; (c) J. J. Kiernicki, M. Zeller and S. C. Bart, Angew. Chem., Int. Ed. Engl., 2017, 56, 1097-1100.

13 (a) L. Natrajan, F. Burdet, J. Pecaut and M. Mazzanti, J. Am. Chem. Soc., 2006, 128, 7152-7153; (b) J. C. Berthet, G. Siffredi, P. Thuery and M. Ephritikhine, J. Chem. Soc., Dalton Trans., 2009, 3478-3494; (c) K. Takao, S. Tsushima, S. Takao, A. C. Scheinost, G. Bernhard, Y. Ikeda and C. Hennig, Inorg. Chem., 2009, 48, 9602-9604; (d) P. Horeglad, G. Nocton, Y. Filinchuk, J. Pecaut and M. Mazzanti, Chem. Commun., 2009, 1843-1845; (e) G. Nocton, P. Horeglad, V. Vetere, J. Pecaut, L. Dubois, P. Maldivi, N. M. Edelstein and M. Mazzanti, J. Am. Chem. Soc., 2010, 132, 495-508; (f) T. W. Hayton and G. Wu, J. Am. Chem. Soc., 2008, 130, 2005-2014; $(g)$ T. W. Hayton and G. Wu, Inorg. Chem., 2008, 47, 7415-7423; $(h)$ P. L. Arnold, B. E. Cowie, M. Suvova, M. Zegke, N. Magnani, E. Colineau, J. C. Griveau, R. Caciuffo and J. B. Love, Angew. Chem., Int. Ed. Engl., 2017, 56, 1077510779; (i) P. L. Arnold, E. Hollis, G. S. Nichol, J. B. Love, J. C. Griveau, R. Caciuffo, N. Magnani, L. Maron, L. Castro, A. Yahia, S. O. Odoh and G. Schreckenbach, J. Am. Chem. Soc., 2013, 135, 3841-3854; (j) P. L. Arnold,
A. F. Pecharman, E. Hollis, A. Yahia, L. Maron, S. Parsons and J. B. Love, Nat. Chem., 2010, 2, 1056-1061; (k) P. L. Arnold, A.-F. Pecharman, R. M. Lord, G. M. Jones, E. Hollis, G. S. Nichol, L. Maron, J. Fang, T. Davin and J. B. Love, Inorg. Chem., 2015, 54, 3702-3710; (l) P. L. Arnold, M. S. Dutkiewicz, M. Zegke, O. Walter, C. Apostolidis, E. Hollis, A. F. Pecharman, N. Magnani, J. C. Griveau, E. Colineau, R. Caciuffo, X. B. Zhang, G. Schreckenbach and J. B. Love, Angew. Chem., Int. Ed. Engl., 2016, 55, 12797-12801.

14 (a) V. Mougel, L. Chatelain, J. Pecaut, R. Caciuffo, E. Colineau, J. C. Griveau and M. Mazzanti, Nat. Chem., 2012, 4, 1011-1017; (b) L. Chatelain, J. P. S. Walsh, J. Pecaut, F. Tuna and M. Mazzanti, Angew. Chem., Int. Ed. Engl., 2014, 53, 13434-13438; (c) P. L. Arnold, D. Patel, C. Wilson and J. B. Love, Nature, 2008, 451, 315-318; (d) L. Chatelain, F. Tuna, J. Pecaut and M. Mazzanti, J. Chem. Soc., Dalton Trans., 2017, 46, 5498-5502; (e) L. Chatelain, F. Tuna, J. Pecaut and M. Mazzanti, Chem. Commun., 2015, 51, 11309-11312; (f) L. Chatelain, J. Pecaut, F. Tuna and M. Mazzanti, Chem.-Eur. J., 2015, 21, 18038-18042; $(g)$ V. Mougel, L. Chatelain, J. Hermle, R. Caciuffo, E. Colineau, F. Tuna, N. Magnani, A. de Geyer, J. Pecaut and M. Mazzanti, Angew. Chem., Int. Ed. Engl., 2014, 53, 819-823.

15 (a) C. Camp, L. Chatelain, V. Mougel, J. Pecaut and M. Mazzanti, Inorg. Chem., 2015, 54, 5774-5783; (b) K. Takao and Y. Ikeda, Inorg. Chem., 2007, 46, 1550-1562.

16 M. Basile, D. K. Unruh, E. Flores, A. Johns and T. Z. Forbes, J. Chem. Soc., Dalton Trans., 2015, 44, 2597-2605.

17 B. D. Stewart, C. Girardot, N. Spycher, R. K. Sani and B. M. Peyton, Environ. Sci. Technol., 2013, 47, 364-371.

18 K. Takao, M. Kato, S. Takao, A. Nagasawa, G. Bernhard, C. Hennig and Y. Ikeda, Inorg. Chem., 2010, 49, 2349-2359. 